\title{
Reduction in the Leptin Concentration as a Predictor of Improvement in Lung Function in Obese Adolescents
}

\author{
Patrícia Leão da Silva ${ }^{a}$ Marco Túlio de Mello ${ }^{b} \quad$ Nadia Carla Cheik $^{c}$ \\ Priscila Lima Sanches ${ }^{a}$ Raquel Munhoz da Silveira Campos ${ }^{a}$ \\ June Carnier $^{a}$ Daniela Inoue ${ }^{a}$ Claudia M.O. do Nascimento ${ }^{d}$ \\ Lila M. Oyamac Lian Tock $^{a}$ Sérgio Tufik ${ }^{d}$ Ana R. Dâmasoa, e, $f$ \\ a Post Graduate Program of Nutrition, ${ }^{\mathrm{b}}$ Department of Psychobiology, Universidade Federal \\ de São Paulo, São Paulo, ' ${ }^{\mathrm{F}}$ ederal University of Uberlândia, Uberlândia, ${ }^{\mathrm{d}}$ Department of \\ Physiology, ${ }^{e}$ Department of Biosciences, ${ }^{f}$ Post Graduate Program of Interdisciplinary Health \\ Sciences, Universidade Federal de São Paulo, São Paulo, Brazil
}

\section{Key Words}

Obesity management $\cdot$ Adolescent $\cdot$ Adipokines $\cdot$ Lung function

\begin{abstract}
Objective: To assess the effects of weight loss on adipokines, asthma-related symptoms, exercise-induced bronchospasm (EIB) and lung function, and to evaluate the role of leptin and adiponectin levels on lung function after treatment in obese adolescents. Methods: 84 postpubertal obese adolescents were enrolled and distributed in quartiles according to weight loss (low $(<2.5 \mathrm{~kg})$, low to moderate $(>2.5$ and $<8 \mathrm{~kg}$ ), moderate $(<8$ and $<14 \mathrm{~kg}$ ) and massive $(<14 \mathrm{~kg})$ ). Body composition was measured by plethysmography, and visceral and subcutaneous fat were detected by ultrasound. Serum levels of adiponectin and leptin were analyzed. Lung function, asthma and EIB were evaluated according to the American Thoracic Society criteria. Patients were submitted to 1 year of interdisciplinary intervention consisting of physiotherapy, medical, nutritional, exercise, and psychological therapy. Results: After treatment the moderate and massive weight loss promoted an increase in adiponectin and adiponectin/ leptin $(A / L)$ ratio as well as a decrease in leptin levels and a reduction in EIB frequency and asthma-related symptoms. Furthermore, the reduction in leptin levels was a predictor factor to improvement in lung function. Conclusion: Interdisciplinary therapy was able to decrease EIB and asthma-related symptoms and to improve pro/anti-inflammatory adipokines. Additionally, the leptin concentration was a predictor factor to explain changes in lung function.
\end{abstract}




\section{Introduction}

Obesity is an important public health problem. According to the last survey, approximately $49 \%$ of the adult Brazilian population is currently obese or overweight. In Brazilian adolescents the prevalence of obesity is also increasing and has more than doubled in the last 20 years [1]. These data reflect a general trend as the incidence of obesity is increasing progressively worldwide [2].

Several studies have documented a negative impact of obesity on lung function and/or exercise-induced bronchospasm (EIB) [3-6]. In addition, obesity has been associated with asthma in both adults and children [7-9], contributing to an increase in asthma severity [10, $11]$.

The mechanism for this association is unclear, but genetic, hormonal, environmental, mechanical, and immunological pathways have been suggested [12]. It is further uncertain which of these various pathways may be the dominant mechanism [13]. Two hypotheses to this relationship have been discussed in more detail: i) the mechanical effects of fat deposit are associated with diaphragm excursion and thoracic compliance [14] and ii) the second have received and involves immunological pathways and the inflammatory role of adipose tissue are involved [15], with the latter being the one receiving the greatest attention.

The obese state is characterized by increases in the serum concentrations of several pro-inflammatory cytokines such as leptin and reduced anti-inflammatory adipokines such as adiponectin [16].

Since its discovery, leptin has been described to play a central role in energy balance control [17]. However, it has another important function: up-regulation of inflammatory responses [18]. Considering the link between obesity and lung function, previous studies demonstrated that the main effects of leptin are on inflammation and lung development $[13,15,19]$. In this sense, Sood et al. [20] verified that leptin concentration was negatively correlated with lung function in adults; however, they did not explore the role of this adipokine on lung function during weight loss. On the other hand, adipocytes are the most important source of adiponectin; however, its concentration is decreased in obese subjects. Conversely, weight loss promotes an increase in adiponectin levels [21,22]. The effects of adiponectin go beyond metabolic effects on fatty acid metabolism and glucose regulation; it also includes an anti-inflammatory effect [23-25]. In this sense, studies that associated adipokines and asthma have documented a protective effect of high adiponectin concentrations [26, 23].

Recently, the evaluation of the adiponectin/leptin (A/L) ratio has been used as a better predictor of inflammatory process and insulin resistance $[21,27,28]$. However, to our knowledge there is no study investigating the role of $\mathrm{A} / \mathrm{L}$ ratio in the relationship between obesity and lung function as well as the effects of different weight loss quartiles on A/L ratio.

Previous studies have demonstrated the important role of interdisciplinary weight loss therapy in the treatment of obesity and related comorbidities [29-31]. However, the effects of different magnitudes of weight loss on lung function are not studied and thus unknown [32].

Therefore, considering the role of adipokines on lung function, and the importance of treatment strategies to control obesity and respiratory conditions, the primary objective of the present study was to evaluate adipokine levels, asthma-related symptoms, EIB frequency and lung function in accordance to magnitude of weight loss. The secondary objective was to assess how treatment-induced leptin and adiponectin concentration changes affect lung function in obese adolescents. 


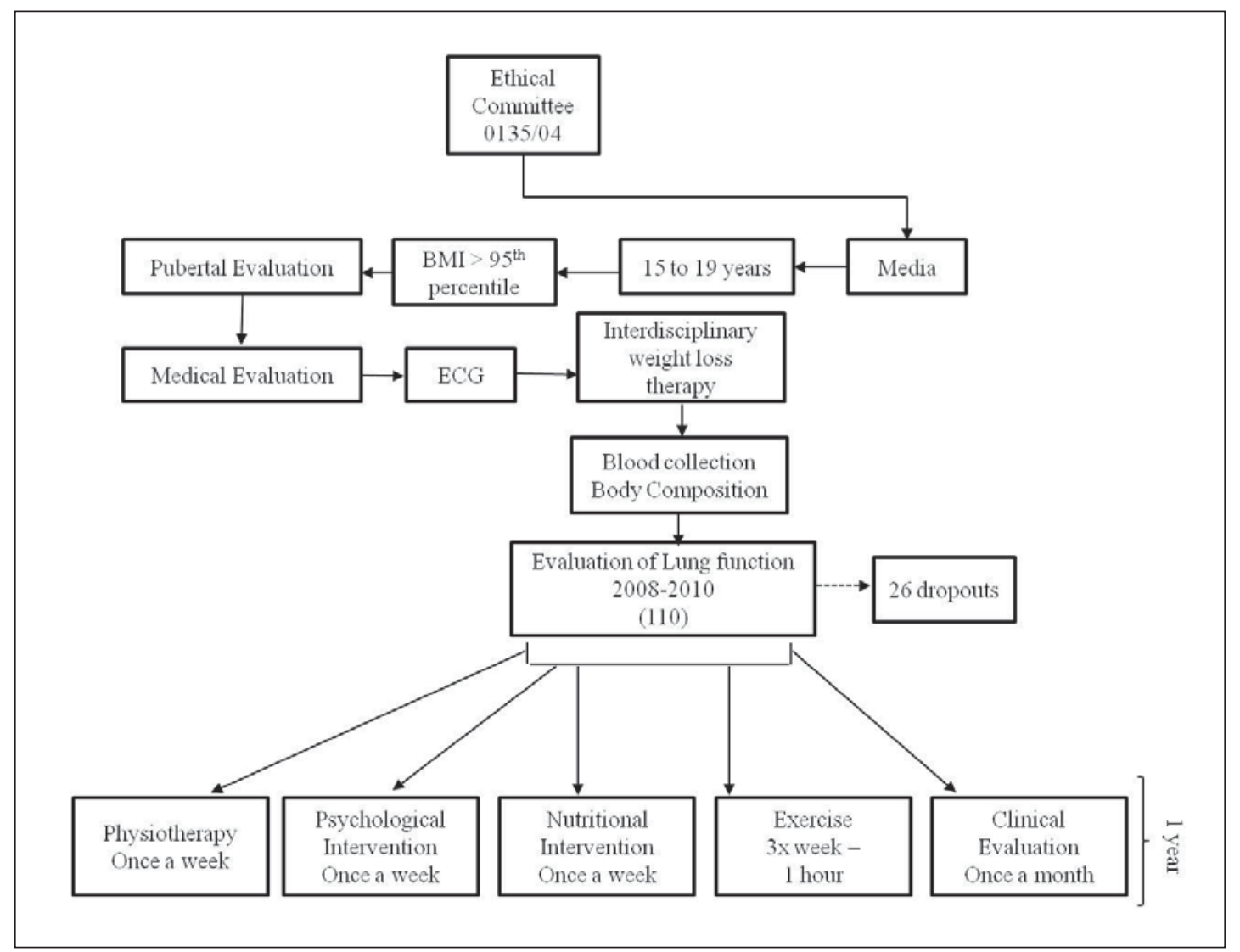

Fig. 1. Study protocol diagram.

\section{Material and Methods}

\section{Population}

A total of 110 adolescents (15 to 19 years old) with simple obesity (BMI > 95th percentile on the CDC reference growth charts) [33] and at the postpubertal stage on the Tanner scale (stage 5) for both boys and girls [34] were enrolled in this study (fig. 1). This study was carried out in accordance with the principles of the Declaration of Helsinki and was formally approved by the Institutional Ethical Committee of the Universidade Federal de São Paulo - UNIFESP (0135/04). Informed consent was obtained from all subjects and/or their parents, and participation of the adolescents and their families was voluntary.

The study occurred at the Sleep Institute in CEPE-GEO - Obesity Interdisciplinary Program, São Paulo. The data were obtained from patients enrolled from 2008 to 2010. Non-inclusion criteria were as follows: metabolic, endocrine or identified genetic diseases; viral diseases; previous drug use; cardiac illnesses and smoking.

\section{Study Protocol and Medical Screening}

Subjects were medically screened, and their pubertal stage and anthropometric measures were evaluated. For all subjects, the procedures were scheduled for the same time of day to preclude any influence of diurnal variation. A physician monthly recorded health and clinical parameters of the participants (fig. 1).

\section{Anthropometric Measurements and Body Composition}

Subjects were weighed while wearing light clothing and no shoes on a Filizola scale to the nearest 0.1 $\mathrm{kg}$. Height was measured to the nearest $0.5 \mathrm{~cm}$ with a wall-mounted stadiometer (Sanny, model ES 2030). BMI was calculated as body weight divided by height squared $\left(\mathrm{kg} / \mathrm{m}^{2}\right)$. 
Leão da Silva et al.: Reduction in the Leptin Concentration as a Predictor of

Improvement in Lung Function in Obese Adolescents

Body composition was measured by plethysmography in a BOD POD body composition system (version 1.69; Life Measurement Instruments, Concord, CA, USA) [35]. Visceral and subcutaneous fat were assessed by ultrasonography as previously described $[29,36]$.

Serum Analysis

Blood samples were collected by a skilled and qualified technician at the outpatient clinic around 8 a.m. after an overnight fast. After collection, the blood was centrifuged for $10 \mathrm{~min}$ at 5,000 r.p.m. and stored at $-70^{\circ} \mathrm{C}$. The materials used for collection were disposable, adequately labeled, and of recognized quality. Adiponectin (Phoenix Pharmaceuticals, Belmont, CA, USA) and leptin (CHEMICON International, Inc., Millipore, Billerica, MA, USA) levels were measured using a commercially available enzyme-linked immunosorbent assay (ELISA) kit according to the manufacturer's instructions.

\section{Evaluation of the Lung Function}

Lung function was measured with a spirometer EasyOne ${ }^{\circledR}$ model 2001 (ndd Medizintechnik AG, Zurich, Switzerland) according to American Thoracic Society (ATS) criteria [37]. The highest of three technically appropriate measurements was recorded. While performing the maneuver, volume-time and flowvolume curves were followed on the screen. Forced vital capacity (FVC; in liters), forced expiratory volume in $1 \mathrm{~s}$ (FEV1; in liters), FEV1/FVC (in \%) and peak expiratory flow (PEF; in l/s) were measured, and predicted values were obtained [38].

The diagnosis of asthma was made according to ATS guidelines [37]. The asthmatic patients had a 6-month or longer history of recurrent chest symptoms such as coughing, dyspnea and wheezing, which were relieved by bronchodilator treatment. They also demonstrated reversible airflow limitation. The International Study of Asthma and Allergy in Childhood (ISAAC) questionnaire was used to assess asthmarelated symptoms [39]. Furthermore, information on anti-asthmatic medication was obtained. The asthmatic patients were evaluated by a pulmonologist. Medical therapy included regular use of inhaled corticosteroids or $\beta 2$-agonists (data not shown).

Tests for maximal volitional ventilation in $15 \mathrm{~s}$ (MVV15) were performed on a computerized spirometry system (EasyOne ${ }^{\circledR}$ model 200; ndd Medizintechnik AG) according to procedures published by the ATS [40]. The greatest value from three repeated measurements was used for subsequent analysis. During all tests of respiratory muscle performance, subjects were seated upright.

\section{Exercise Challenge Test}

A standardized exercise challenge consisted of $8 \mathrm{~min}$ on a treadmill and was initiated at a speed of 1 $\mathrm{km} / \mathrm{h}$ and a $0 \%$ inclination, increasing by $1.5 \mathrm{~km} / \mathrm{h}$ and a $2.5 \%$ inclination after each 30 -second period for $2 \mathrm{~min}$ until a speed of $6 \mathrm{~km} / \mathrm{h}$ and a level of inclination of $10 \%$ was achieved. The challenge was conducted by having patients run for $8 \mathrm{~min}$ while inhaling air through their mouth, at a workload that increased the heart rate to $80 \%$ of the age-predicted maximum [41]. During the days of testing, mean temperature and relative humidity were $25 \pm 5{ }^{\circ} \mathrm{C}$ and $41 \pm 10 \%$, respectively. The study was conducted in the afternoon (1:00 to 5:00 p.m.).

Spirometric measurements were made immediately before and at 2, 5, 10, 15, 20, 25 and $30 \mathrm{~min}$ after exercise. To measure EIB, the maximal change in FEV1 was calculated as $100 \times((\mathrm{FEV} 1$ at baseline - lowest FEV1 after exercise) / FEV1 at baseline). EIB diagnosis was defined as a 15\% or greater reduction in FEV1 after exercise compared to FEV1 at baseline.

\section{Research Design}

The use of interdisciplinary intervention has been suggested by the World Health Organization [42]. All measurements were performed at baseline and after 1 year of therapy.

\section{Physiotherapy}

The volunteers were submitted to physical therapy evaluation at baseline. Subsequently, all subjects were accompanied by a physiotherapist during the therapy in order to prevent musculoskeletal injuries. Additionally, the volunteers had lessons regarding topics such as postural habits, prevention of musculoskeletal injuries and prevention and management of asthma symptoms and EIB occurrence. During exercise therapy, the patients with asthma were accompanied by a physical therapist who controlled their symptoms. 
Table 1. Quartiles of weight loss of obese adolescents after 1year of interdisciplinary intervention
DOI: $10.1159 / 000345840$

Leão da Silva et al.: Reduction in the Leptin Concentration as a Predictor of Improvement in Lung Function in Obese Adolescents

$\begin{array}{ll}\text { 1st }(<2.5 \mathrm{~kg}) & \text { Low } \\ \text { 2nd }(>2.5 \text { and }<8 \mathrm{~kg}) & \text { Low to moderate } \\ \text { 3rd }(>8 \text { and }<14 \mathrm{~kg}) & \text { Moderate } \\ \text { 4th }(>14 \mathrm{~kg}) & \text { Massive }\end{array}$

\section{Nutritional Therapy}

Once a week for 1 year, adolescents had nutritional lessons regarding topics such as food pyramid, food record, weight loss diets, diet and light concepts, fat and cholesterol, and eating disorders. Energy intake was set at the levels recommended by the dietary reference for subjects with low levels of physical activity of the same age and gender [43]. A 3-day dietary record was made for each adolescent to help his/ her parents. Portions were measured in terms of familiar volumes and sizes. The nutritionist explained to the parents and the adolescents how to record food consumption. These dietary data were transferred to a computer by the same nutritionist, allowing for nutrient composition analysis by a PC program developed at the Universidade Federal de São Paulo (Nutwin software, for windows, 1.5 version, 2002) based on Western and local food tables.

\section{Physical Therapy}

An aerobic and resistance training regimen was performed 3 times a week for 1 year. Each session included $30 \mathrm{~min}$ of aerobic training plus $30 \mathrm{~min}$ of resistance training. Aerobic training consisted of running on a motor-driven treadmill (Life Fitness, Model TR 9700HR; São Paulo, Brazil) at the cardiac frequency intensity of ventilatory threshold I ( $\pm 4 \mathrm{bpm})$, which was determined by the results of an initial oxygen uptake test for aerobic exercise (cycle ergometer and treadmill). In addition, the maximal 02 consumption (VO2max) values of the oxygen uptake test were obtained.

The physiologists controlled the cardiac frequency, which was measured with a cardiometer at 5-min intervals during all training sessions (Polar, Model FS1 dark blue; Lake Success, NY, USA). The exercise program was based on the American College of Sports Medicine (ACSM) recommendations [44].

\section{Psychological Therapy}

During 1 year of interdisciplinary therapy, the adolescents received psychological orientation for $1 \mathrm{~h}$ in a weekly group session. A psychologist discussed body image and eating disorders as well as binge eating disorders and their signs, symptoms, and health consequences. The psychologist also discussed the relationship between emotions and food as well as familial problems in a group setting. Individualized psychological therapy was recommended if behavioral alterations including depression and anxiety symptoms or poor dietary habits such as bulimia, anorexia nervosa and binge eating became apparent [30].

\section{Statistical Analysis}

Statistical analyses were performed using STATISTICA version 7.0 for Windows StatSoft Inc., Tulsa, OK, USA). The Gaussian distribution of variables was verified with a Shapiro-Wilk's W test, and variables with normal distribution were expressed as the mean \pm standard deviation (SD), while variables without normal distribution were expressed as medians (minimum and maximum) in a descriptive table. Nonparametric methods were used when appropriate.

The comparisons between the measurements of the parametric variables before and after intervention were determined by paired Student's t-tests. The Wilcoxon signed rank and Mann-Whitney U tests were used to analyze the non-parametric variables. Comparisons between groups were made using unpaired Student's t-tests (parametric variables) or the Mann-Whitney test (non-parametric variables). The chi-square test was used to evaluate gender, EIB frequency and asthma-related symptoms between the times of evaluation. Subjects were distributed in quartiles according to the magnitude of weight loss (table 1).

We assessed the correlation between $\Delta$ values of variables ( $\Delta=$ the difference of values between 1 year and baseline). Pearson's correlation coefficients were calculated to assess possible relationships between normally distributed variables. For non-normal measurements, Spearman's correlation coefficients were used. 
Multiple regression analysis was used to ascertain the predictor factors to changes in lung function. The lung function variables (FVC, FEV1 or PEF) were set as dependent variables in different models, and body mass, A/L ratio or leptin levels were set as independent variables; all analysis only were adjusted for weight loss quartiles and asthma diagnosis.

Furthermore, Grubb's test was used to detect outliers in data using GraphPad Prism ${ }^{\circledR}$ version 5.0 for Windows (GraphPad Software, Inc., La Jolla, CA, USA). The results were considered statistically significant at the level of $\mathrm{p}<0.05$.

\section{Results}

At the beginning of the therapy, 110 obese adolescents were enrolled in the program. However, only 84 patients completed 1 year of therapy with more than $75 \%$ of treatment sessions. It is important to note that there were no differences for all variables between those who completed the therapy and the last known data from those who did not. The main reasons for dropping out were financial and family problems, followed by school and job opportunities (fig. 1).

For analysis of the variables studied, the volunteers were divided in quartiles of weight loss (table 1). At baseline, we did not find significant differences in age and BMI between groups once the studied population was paired by these variables according to gender. There were no statistically significant differences between genders in the groups for all variables (data not shown).

\section{Results of the Low Weight Loss Quartile}

After 1 year of interdisciplinary intervention, low weight loss did not promote a significant reduction in any of the anthropometric and lung function variables (table 2). In addition, the low weight loss group did not present any alteration in adipokine profile and A/L ratio (table 3) and did not reduce asthma-related symptoms and EIB frequency after therapy (table 4). However, the VO2 max values increased after therapy (table 2).

\section{Results of the Low to Moderate Weight Loss Quartile}

After therapy the low to moderate weight loss group showed significantly decreased fat mass and increased fat free mass percentage. Furthermore, we observed a significant increase in lung function variables and VO2 max values (table 2). However, we did not observe any alteration in adipokines profile and A/L ratio (table 3) On the other hand, asthma-related symptoms after therapy were reduced in these subjects (table 4).

\section{Results of the Moderate Weight Loss Quartile}

The moderate weight loss promoted a significant reduction in all anthropometric variables and a significant increase in lung function variables and VO2 max values (table 2). Moreover,an increase in adiponectin concentration as well in A/L ratio and a decrease in leptin concentration after therapy could be demonstrated (table 3). In addition, the subjects in the moderate weight loss quartile presented with higher frequency of EIB than those of the fourth quartile at baseline. Nevertheless, the asthma-related symptoms and EIB frequency were reduced after therapy (table 4).

\section{Results of the Massive Weight Loss Quartile}

In the massive weight loss group, a significant reduction in all anthropometric variables and a significant increase in lung function variables and VO2 max values were observed after therapy (table 2). Indeed, it could be shown that the massive weight loss promoted an 
్ㅗำ

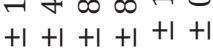

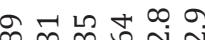

$\approx$ เ 0 ด

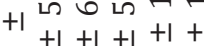
品寻穴和约琈

an $\underset{\rightarrow}{\exists}$ $+1+1+1+1+1+1$

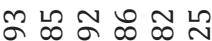

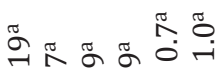
$+1+1+1+1+1+1$

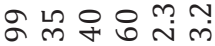

$\stackrel{\infty}{\rightarrow-1}$ $\rightarrow \infty$

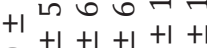

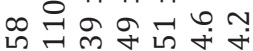

$\stackrel{-1}{\rightarrow}$ ก $+1+1+1+1+1+1$ 항하우요욯

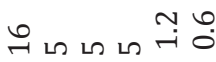
$+1+1+1+1+1+1$

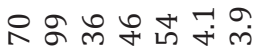
$\stackrel{\neg}{\rightarrow} \sim \infty \stackrel{0}{\rightarrow} \stackrel{\text { ? }}{0}$ $+1+1+1+1+1+1$

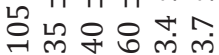

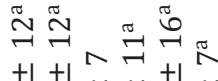
$+1+1 \hat{+1}+1+1$ 음엄송유 슷

の $+1+1+1+1+1+1$

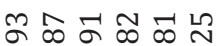

윽 $+17+1+1+1$ ᄂ $\stackrel{\infty}{\rightarrow} \stackrel{\infty}{\sim}$

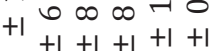
응 $m \sim n$

$\infty \exists \exists$ 극 $+1+1+1+1+1+1$

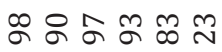

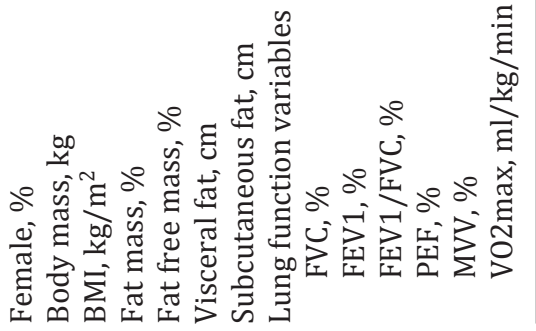

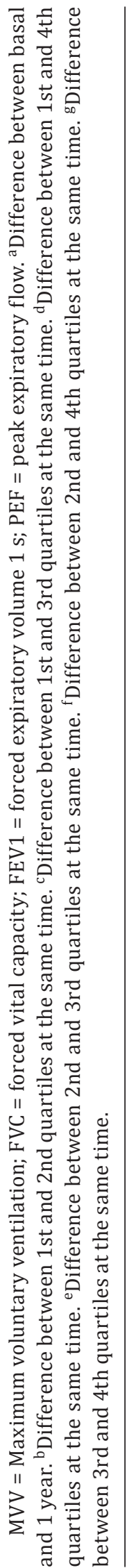



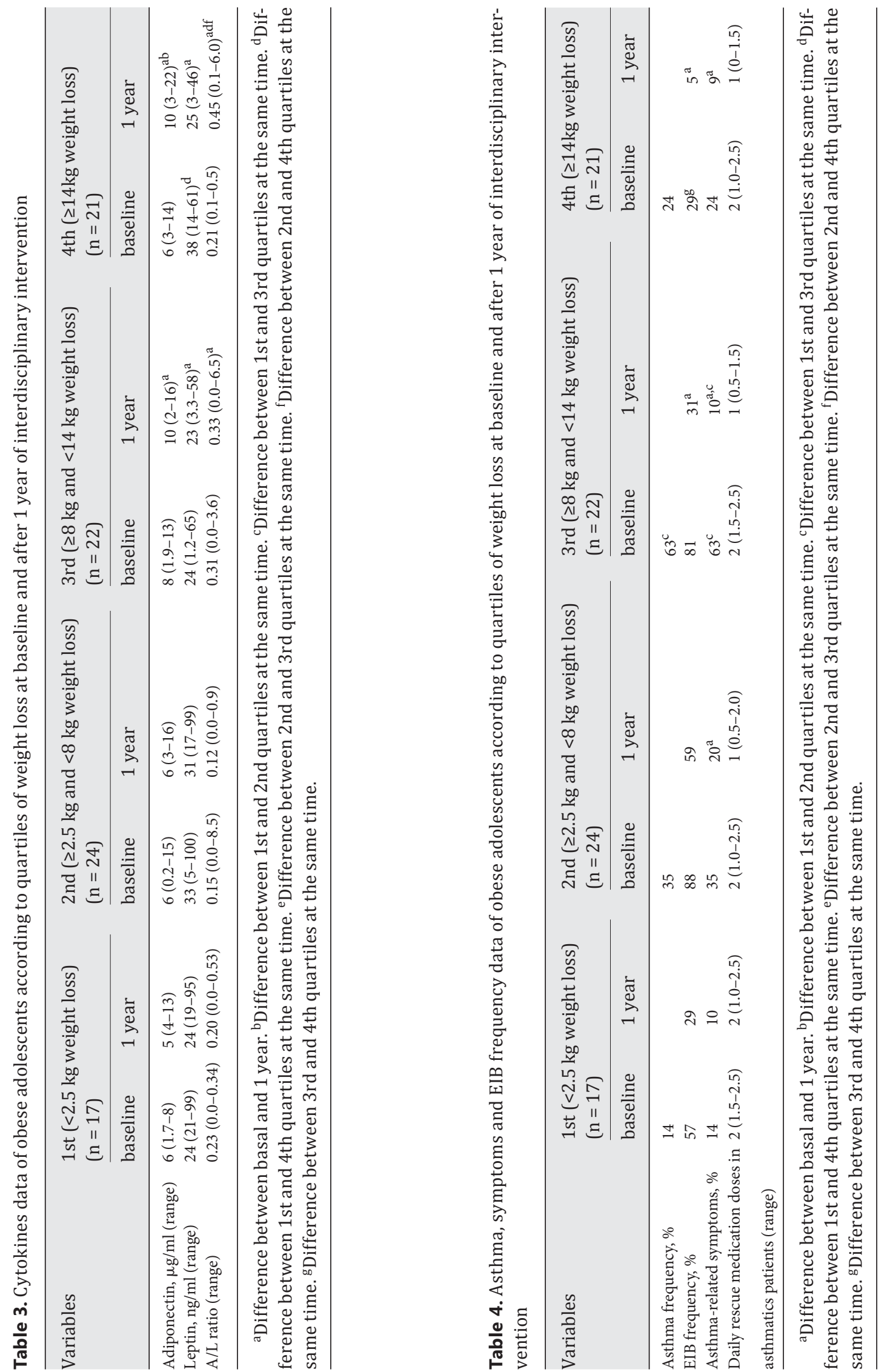


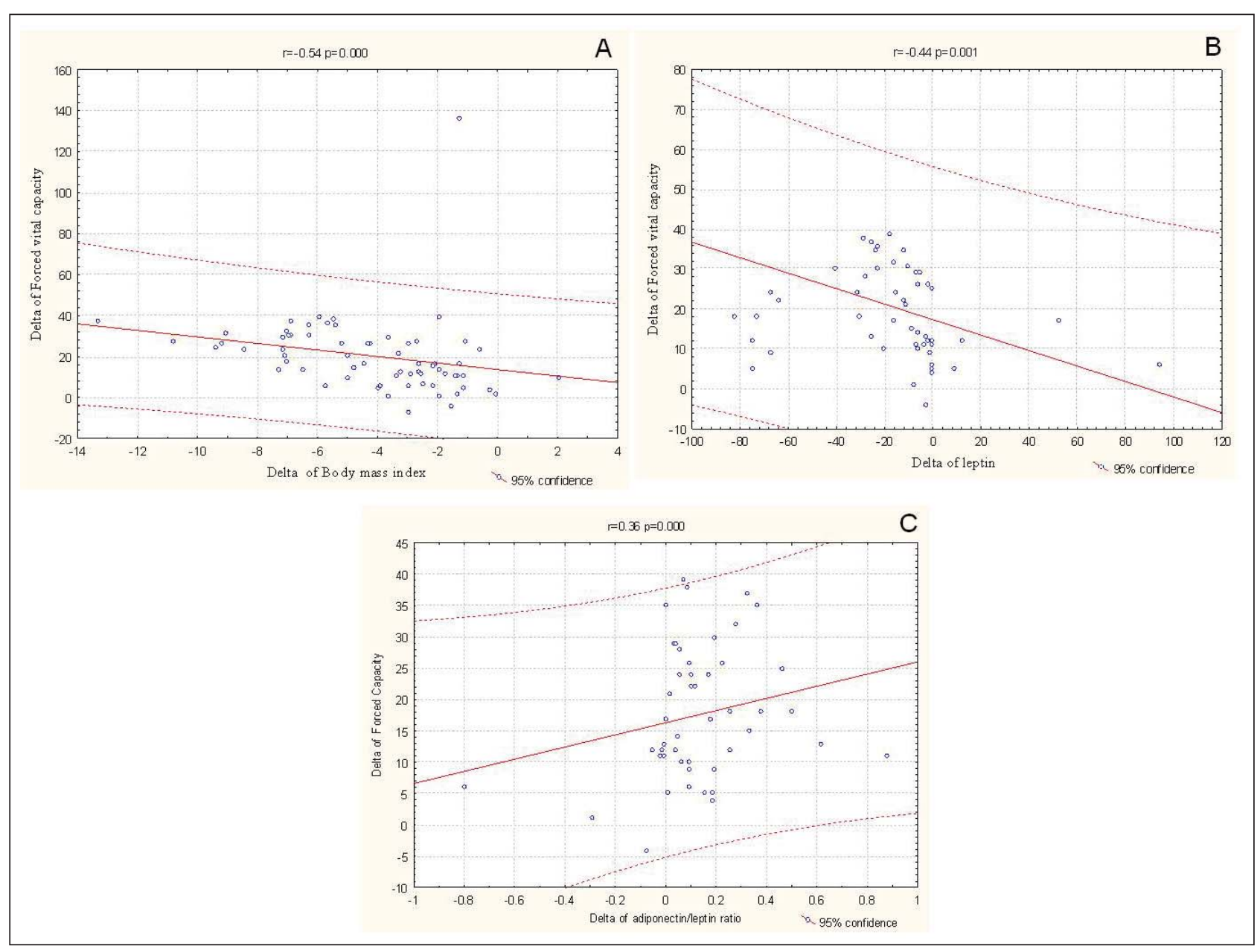

Fig. 2. Correlation coefficients between delta of FVC and delta of A BMI, B $\Delta$ leptin and C $\Delta \mathrm{A} / \mathrm{L}$ ratio after 1 year of intervention.

increase in adiponectin and A/L ratio and a decrease in leptin concentrations after therapy. On the other hand, higher values of leptin were observed in the fourth quartile compared to the low weight loss quartile at baseline (table 3). The asthma symptoms as well as EIB frequency were reduced after massive weight loss (table 4).

\section{Results of All Analyzed Patients}

The absolute value of changes after therapy in FVC exhibited a negative correlation with BMI $(r=-0.54, p=0.000)$ and leptin concentration $(r=-0.44, p=0.001)$ and were positively correlated with A/L ratio $(r=0.36, p=0.000)$ (fig. 2). Furthermore, the changes in FEV1 were negatively correlated with BMI $(r=-0.57, p=0.001)$ and leptin concentration $(r=-0.41$, $\mathrm{p}=0.000)$, but positively correlated with $\mathrm{A} / \mathrm{L}$ ratio $(\mathrm{r}=0.33, \mathrm{p}=0.001)$ (fig. 3 ). In addition, $\Delta$ PEF was negatively correlated with BMI $(r=-0.34, p=0.001)$ and leptin concentration $(r$ $=-0.37, \mathrm{p}=0.000$ ) (fig. 4).

As shown in table 5, multiple linear regression analysis demonstrated that $\Delta$ leptin concentration was an independent factor to changes in FVC, FEV1 and PEF values in obese adolescents. Furthermore, $\triangle$ BMI was an independent predictor to changes only for the FEV1 values. 


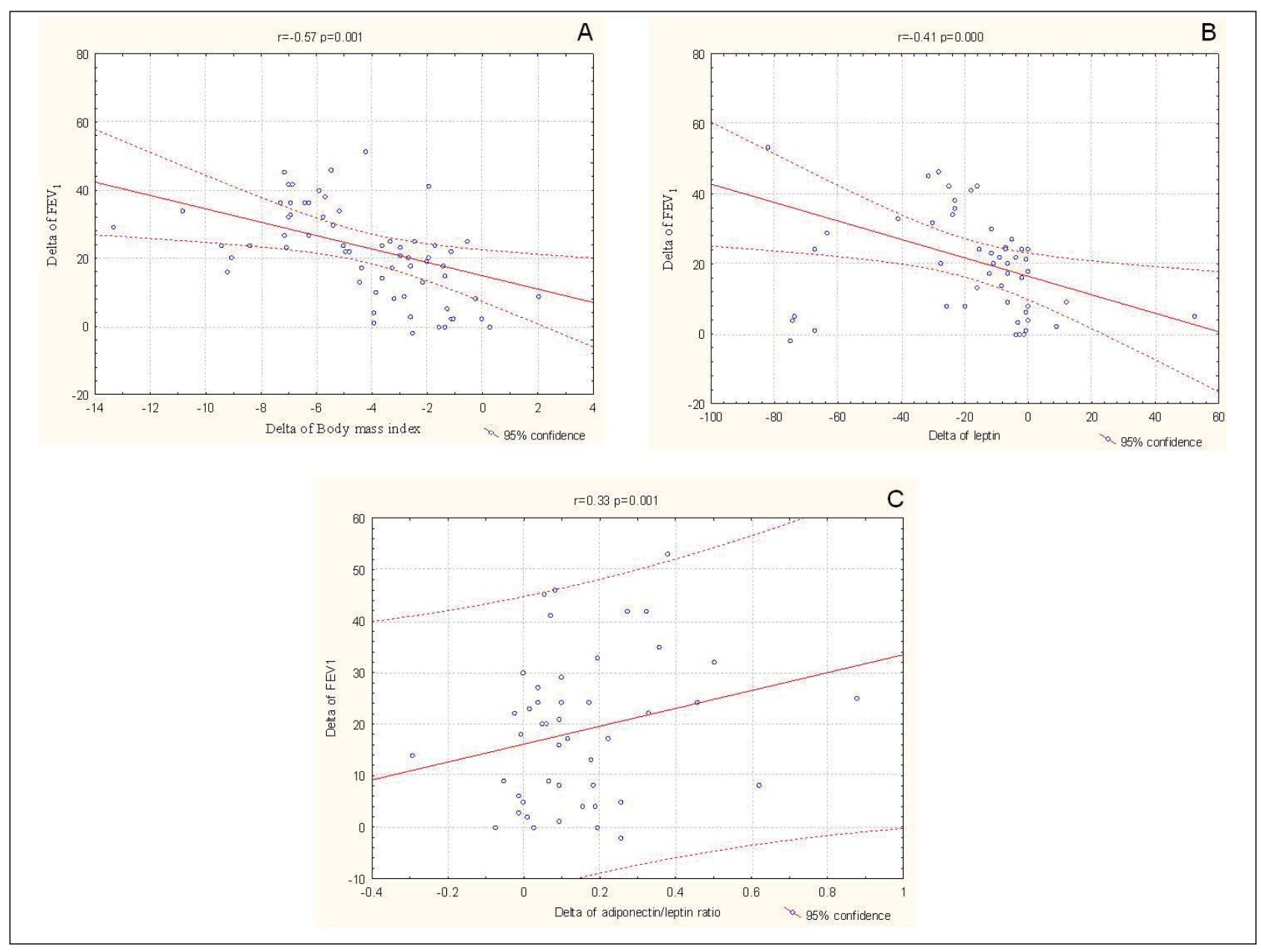

Fig. 3. Correlation coefficients between $\Delta$ FEV1 and A $\Delta$ BMI, B $\Delta$ leptin and C $\Delta$ A/L ratio after 1 year of intervention.

\section{Discussion}

Previous studies demonstrated the important role of interdisciplinary therapy in the treatment of obesity [22, 29-31]. However, the influence of this kind of therapy according to magnitude of weight loss on lung function, asthma-related symptoms, and EIB had not been studied yet. It could be demonstrated in our study that 1 year of interdisciplinary therapy was able to improve lung function and to decrease asthma-related symptoms and EIB frequency, which is paralleled by an improvement in pro/anti- inflammatory adipokine profile in obese adolescents with moderate and massive weight loss.

Obesity negatively affects several respiratory physiologic parameters such as compliance, lung volume and airway responsiveness [14]. The mechanisms underlying these effects are likely to be complex and may include mechanical effects of central fat deposit on the diaphragm and the chest wall that would cause a reduction in diaphragm excursion and consequently a decrease in thoracic compliance and lung volumes limiting the expansion of the lungs $[32,45]$ as well as inflammatory processes related to adipose tissue release of 


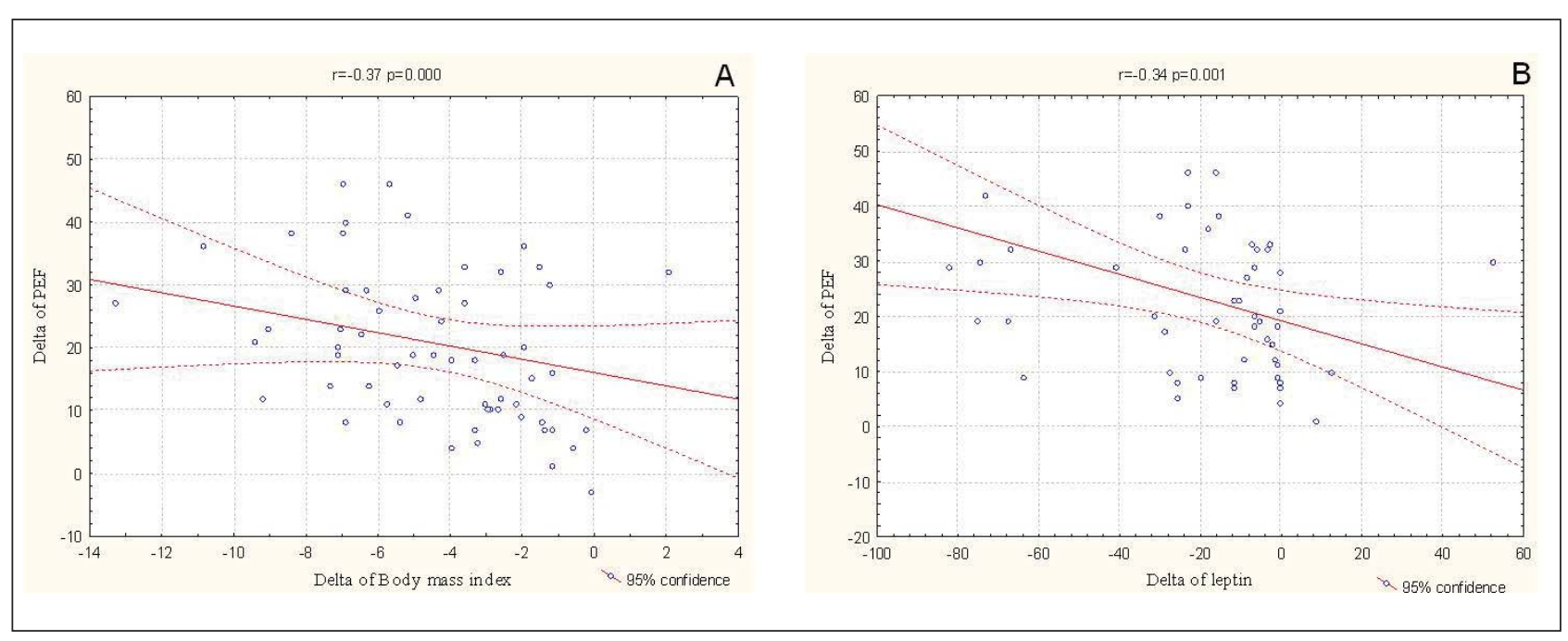

Fig. 4. Correlation coefficients between delta of PEF and A $\Delta$ BMI and B $\Delta$ leptin after 1 year of intervention.

Table 5. Multiple regression analysis for the determinants of changes in FVC, FEV1 or PEF

\begin{tabular}{|c|c|c|c|c|c|c|}
\hline \multirow[t]{2}{*}{ Independent variable } & \multicolumn{2}{|l|}{$\Delta \mathrm{FVC}$} & \multicolumn{2}{|l|}{$\Delta$ FEV1 } & \multicolumn{2}{|l|}{$\Delta \mathrm{PEF}$} \\
\hline & B coefficient & $\mathrm{p}$ value & B coefficient & $\mathrm{p}$ value & B coefficient & $\mathrm{p}$ value \\
\hline$\Delta \mathrm{BMI}^{*}$ & -1.53 & 0.51 & -2.05 & 0.009 & -1.02 & 0.158 \\
\hline$\Delta$ Leptin* & -0.36 & 0.007 & -0.62 & 0.000 & -0.31 & 0.038 \\
\hline$\Delta$ Adiponectin/leptin ratio* & 2.67 & 0.43 & 1.58 & 0.63 & 2.35 & 0.40 \\
\hline
\end{tabular}

${ }^{*}$ Analyses are adjusted only for weight loss quartiles and asthma diagnosis.

adipokines, which possess anti-inflammatory effects, e.g. adiponectin, or pro-inflammatory properties, e.g. leptin $[13,15]$.

One of the main findings in the present investigation was that leptin concentration reduction was a predictor factor for improvements in FVC, FEV1 and PEF, while the $\Delta$ BMI was predictor factor only for FEV1. These findings suggest a close association between leptin and lung function, which can be explained by the effects of leptin on inflammation and lung development [26].

Leptin has pro-inflammatory properties as it stimulates the release of pro-inflammatory cytokines such as IL-6 and TNF- $\alpha$ from the adipose tissue [46] and a negative modulatory effect on regulatory $\mathrm{T}$ cells. Accordingly, previous studies have demonstrated that leptin concentrations are increased during allergic reactions in the airways [47] and play a role in the intrauterine, neonatal, and post-natal lung development [47, 48]. Moreover, leptin concentrations are increased in obese subjects, including adolescents [17, 49]. Thus, it is important to note that in the present study a decrease in leptin concentration after moderate and massive weight loss could be observed, but 1 year of treatment was not able to normalize the leptin values. Thus, our results and data from literature corroborate the hypothesis that leptin plays a central role in inflammatory processes linking obesity and pulmonary diseases. 
Another important result in the present study was that adiponectin concentration and A/L ratio significantly increased after moderate and massive weight loss, a finding which was in agreement with previous studies $[21,22]$. The anti-inflammatory adipokine adiponectin is one of most abundant gene products in adipose tissue. It has been shown to promote a protective effect in asthma $[23,26]$. The anti-inflammatory effects of adiponectin include inhibition of pro-inflammatory cytokines such TNF- $\alpha$ and IL-6, as well as stimulation of anti-inflammatory cytokines such IL-10 and IL-1 receptor antagonist [50].

A positive association between change in $\mathrm{A} / \mathrm{L}$ ratio and lung function was show in the present investigation, reinforcing the importance of studying therole of pro/anti-inflammatory adipokines in the control of obesity and respiratory diseases. In addition, the increase in $\mathrm{A} / \mathrm{L}$ ratio after therapy is in agreement with the results of a previous study on obese adolescents boys [21]. According to Inoue et al. [27], this increase in A/L ratio may reflect enhanced insulin sensitivity and a reduced cardiovascular risk of the obese adolescents.

Previous studies on obese subjects have demonstrated that the decrease in EIB frequency after weight loss was accompanied by an improvement in lung function [51, 52]. However, these studies did not relate the decreased frequencies of EIB to the magnitude of weight loss. One important finding of our investigation was that moderate and massive weight loss, resulted in a reduction of asthma-related symptoms and EIB frequency, suggesting that a reduction of $10-20 \%(11-21 \mathrm{~kg})$ in body mass was necessary to affect EIB prevalence in our patients. Aaron et al. [53] were able to show that a weight loss $\geq 20 \mathrm{~kg}$ in women receiving restricted calorie diet improved lung function and reduced asthma-related symptoms but did not influence airway responsiveness.

Obese subjects showed an increased EIB frequency when compared with lean individuals [4-6]. Moreover, EIB might be a restriction to practice physical exercise and thus contribute to sedentarism, thus being part of the vicious circle of causes and consequences linking obesity and respiratory conditions [54]. Reduction of EIB frequency, therefore, might be an important cornerstone in the integrated clinical approach to control both obesity and respiratory conditions.

One limitation of our study is the lack of a control group. However, it should be mentioned that the primary objectives of the present study were to assess the effects of weight loss magnitude and how lung function is affected by changes in pro/anti-inflammatory adipokine levels.

In conclusion, the leptin concentration could be identified as an predictor factor to explain changes in lung function. Furthermore, moderate and massive weight loss was accompanied by a reduction in EIB frequency and asthma-related symptoms resulting in an improvement of lung function in obese adolescents submitted to 1 year of interdisciplinary weight loss therapy.

\section{Acknowledgements}

Financial supportwas provided by AFIP, CNPq,CAPES, FAPESP 2008/53069-0, FAPESP 2006/00684-3, FAPESP 98/14303-3, CENESP, FADA, FAPESP (CEPID/Sleep No. 98/14303-3 S.T), FAPEMIG processo №: APQ-01102-09, and UNIFESP. The CEPE-GEO Obesity Interdisciplinary Program was supported by UNIFESP. Special thanks go to the patients and their parents. 


\section{Ethical Approval}

Project approval was obtained from Human Research Ethics Committee of Universidade Federal de São Paulo - UNIFESP (0135/04).

\section{Disclosure Statement}

The authors have disclosed no conflicts of interest.

\section{References}

1 Instituto Brasileiro de Geografia e Estatística (IBGE): Sociodemographic and Health Indicators in Brazil 2009 (in Portuguese). 2010. www.ibge.gov.br (last accessed November 15, 2012).

2 Ogden CL, Carroll MD, Curtin LR, Lamb MM, Flegal KM: Prevalence of high body mass index in U.S. children and adolescents, 2007-2008. JAMA 2010;303:242-249.

3 Ochs-Balcom HM, Grant BJ, Muti P, Sempos CT, Freudenheim JL, Trevisan M, Cassano PA, Iacoviello L, Schünemann HJ: Pulmonary function and abdominal adiposity in the general population. Chest 2006;129: 853-862.

4 Ulger Z, Demir E, Tanaç R, Gökşen D, Gülen F, Darcan S, Can D, Coker M: The effect of childhood obesity on respiratory function tests and airway hyperresponsiveness. Turk J Pediatr 2006;48:43-50.

- 5 Del Río-Navarro BE, Cisneros-Rivero M, Berber-Eslava A, Espínola-Reyna G, Sienra-Monge J: Exercise induced bronchospasm in asthmatic and non-asthmatic obese children. Allergol Immunopathol (Madr) 2000;28:5-11.

6 Lopes WA, Radominski RB, Rosário Filho NA, Leite N: Exercise-induced bronchospasm in obese adolescents. Allergol Immunopathol (Madr) 2009;37:175-179.

- 7 Figueroa-Munoz JI, Chinn S, Rona RJ: Association between obesity and asthma in 4-11 year old children in the UK. Thorax 2001;56:133-137.

- 8 Ford ES, Mannino DM, Redd SC, Mokdad AH, Mott JA: Body mass index and asthma incidence among USA adults. Eur Respir 2004;24:740-744.

- 9 Maniscalco M, Zedda A, Faraone S, Cerbone MR, Cristiano S, Giardiello C, Sofia M: Weight loss and asthma control in severely obese asthmatic females. Respir Med 2008;102:102-108.

10 Cassol V, Rizzato TM, Teche SP, Basso DF, Centenaro DF, Maldonado M, Moraes EZ, Hirakata VN, Solé D, Menna-Barreto SS: Obesity and its relationship with asthma prevalence and severity in adolescents from southern Brazil. J Asthma 2006;43:57-60.

11 Akerman MJ, Calacanis CM, Madsen MK: Relationship between asthma severity and obesity. J Asthma 2004; 41:521-526.

12 Sood A: Does obesity weigh heavily on the health of the human airway? J Allergy Clin Immunol 2005;115: 921-924.

13 Sood A: Obesity, adipokines, and lung disease. J Appl Physiol 2010;108:744-753.

14 Sood A: Altered resting and exercise respiratory physiology in obesity. Clin Chest Med 2009;30:445-454.

15 Jartti T, Saarikoski L, Jartti L, Lisinen I, Jula A, Huupponen R, Viikari J, Raitakari OT: Obesity, adipokines and asthma. Allergy 2009;64:770-777.

16 Scherer PE: Adipose tissue: from lipid storage compartment to endocrine organ. Diabetes 2006;55:15371545.

17 Frühbeck G, Jebb SA, Prentice AM: Leptin: physiology and pathophysiology. Clin Physiol 1998;8:399-419.

-18 Lord GM, Matarese G, Howard JK, Baker RJ, Bloom SR, Lechler RI: Leptin modulates the T-cell immune response and reverses starvation-induced immunosuppression. Nature 1998;394:897-901.

19 Nair P, Radford K, Fanat A, Janssen LJ, Peters-Golden M, Cox PG: The effects of leptin on airway smooth muscle responses. Am J Respir Cell Mol Biol 2008;39:475-481.

20 Sood A, Ford ES, Camargo Jr CA: Association between leptin and asthma in adults. Thorax 2006;61:300305.

21 M Elloumi, O Ben Ounis, E Makni, E Van Praagh, Z Tabka, G Lac: Effect of individualized weight-loss programmes on adiponectin, leptin and resistin levels in obese adolescent boys. Acta Pædiatrica 2009;98: 1487-1493.

22 Sanches PL, Mello MT, Elias N, Fonseca FAH, Piano A, Carnier J, Oyama LM, Tock L, Tufik S, Dâmaso AR: Improvement in HOMA-IR is an independent predictor of reduced carotid intima-media thickness in obese adolescents participating in an interdisciplinary weight-loss program. Hypertens Res 2011;34:232-238.

23 Shore SA, Terry RD, Flynt L, Xu A, Hug C: Adiponectin attenuates allergen induced airway inflammation and hyperresponsiveness in mice. J Allergy Clin Immunol 2006;118:389-395. 
Leão da Silva et al.: Reduction in the Leptin Concentration as a Predictor of

Improvement in Lung Function in Obese Adolescents

24 Fantuzzi G: Adipose tissue, adipokines, and inflammation. J Allergy Clin Immunol 2005;115:897-909.

25 Bruun JM, Lihn AS, Verdich C, Pedersen SB, Toubro S, Astrup A, Richelsen B: Regulation of adiponectin by adipose tissue-derived cytokines: in vivo and in vitro investigations in humans. Am J Physiol Endocrinol Metab 2003;285:E527-533.

-26 Kim KW, Shin YH, Lee KE, Kim ES, Sohn MH, Kim KE: Relationship between adipokines and manifestations of childhood asthma. Pediatr Allergy Immunol 2008;19:535-540.

27 Inoue M, Maehata E, Yano M, Taniyama M, Suzuki S: Correlation between the adiponectin-leptin ratio and parameters of insulin resistance in patients with type 2 diabetes. Metabolism 2005;54:281-286.

28 Jung C-H, Rhee E-J, Choi J-H, Bae J-C, Yoo S-H, Kim W-J, Park C-Y, Mok JO, Kim CH, Lee WY, Oh KW, Park S-W, Kim S-W: The relationship of adiponectin/leptin ratio with homeostasis model assessment insulin resistance index and metabolic syndrome in apparently healthy Korean male adults. Korean Diabetes J 2010; 34:237-243.

29 Tock L, Prado WL, Caranti DA, Cristofalo DMJ, Lederman H, Fisberg M, Siqueira KO, Stella SG, Antunes HK, Cintra IP, Tufik S, de Mello MT, Dâmaso AR: Non-alcoholic fatty liver disease in obese adolescents after multidisciplinary therapy. Eur J Gastroenterol Hepatol 2006;18:1241-1245.

-30 Lofrano-Prado MC, Antunes HK, do Prado WL, de Piano A, Caranti DA, Tock L, Carnier J, Tufik S, de Mello MT, Dâmaso AR: Quality of life in Brazilian obese adolescents: effects of a long-term multidisciplinary lifestyle therapy. Health Qual Life Outcomes 2009;7:61.

-31 Caranti DA, de Mello MT, Prado WL, Tock L, Siqueira KO, de Piano A, Lofrano MC, Cristofalo DM, Lederman H, Tufik S, Dâmaso AR: Short- and long-term beneficial effects of a multidisciplinary therapy for the control of metabolic syndrome in obese adolescents. Metabolism Clinical and Experimental 2007;56:1293-1300.

-32 Lugogo NL, Kraft M, Dixon AE: Does obesity produce a distinct asthma phenotype? J Appl Physiol 2010;108: 729-734.

33 Centers for Disease Control and Prevention:. [(Updates on 11 January 2007; accessed on 15 August 2007). Prevalence of overweight among children and adolescents: United States 1999-2002. Hyattsville, National Center for Health Statistics, 2007 (updates on January 11, 2007; accessed on August 15, 2007). www.cdc.gov/ nchs/products/pubs/pubd/hestats/overwght99.htm.

-34 Tanner JM, Whitehouse RH: Clinical longitudinal standards for height, weight, weight velocity and stages of puberty. Arch Dis Child 1976;51:170-179.

-35 Fields DA, Hunter GR, Goran MI: Validation of the BOD POD with hydrostatic weighing: influence of body clothing. Int J Obes Relat Metab Disord 2000;24:200-205.

-36 Ribeiro-Filho FF, Faria AN, Azjen S, Zanella MT, Ferreira SR: Methods of estimation of visceral fat: advantages of ultrasonography. Obes Res 2003;11:1488-1494.

37 American Thoracic Society: Guidelines for assessing and managing asthma risk at work, school, and recreation. Am J Respir Crit Care Med 2004;169:873-881.

-38 Knudson RJ, Lebowitz MD, Holberg CJ, Burrows B: Changes in the healthy maximal expiratory flow-volume curve with growth and aging. Am Rev Respir Dis 1983;127:725-734.

39 Weiland SK, Björkstén B, Brunekreef B, Cookson WO, von Mutius E, Strachan DP; International Study of Asthma and Allergies in Childhood Phase II Study Group: International Study Protocol: International Study of Asthma and Allergies in Childhood (ISAAC): rationale and methods. Eur Respir J 1995;8:483-491.

$\checkmark 40$ American Thoracic Society/European Respiratory Society: ATS/ERS statement on respiratory muscle testing. Am J Respir Crit Care Med 2002;166:518-624.

-41 Carlsen KH, Engh G, Mork M: Exercise-induced bronchoconstriction depends on exercise load. Respir Med 2000;94:750-755.

42 World Health Organization (WHO): Report of a WHO consultation; in Alwan A, King H (eds):. Definition, Diagnosis and Classification of Diabetes Mellitus and its Complications. Part 1:Diagnosis and Classification of Diabetes Mellitus. Geneva, Department of Noncommunicable Disease Surveillance, World Health Organization, 1999, pp 1-59.

43 NRC (National Academic Press) Dietary Reference Intake: Applications in Dietary Assessment. Washington, DC, National Academic Press; 2001.

$\checkmark 44$ American College of Sports Medicine: Progression models in resistance training for healthy adults. Med Sci Spor Exerc 2002;34:364-380.

45 Parameswaran K, Todd DC, Soth M: Altered respiratory physiology in obesity. Can Respir J 2006;13:203210.

-46 Faggioni R, Jones-Carson J, Reed DA, Dinarello CA, Feingold KR, Grunfeld C, Fantuzzi G: Leptin deficient (ob/ ob) mice are protected from T cell-mediated hepatotoxicity: role of tumor necrosis factor alpha and IL-18. Proc Natl Acad Sci U S A 2000;97:2367-2372.

-47 Bruno A, Pace E, Chanez P, Gras D, Vachier I, Chiappara G, La Guardia M, Gerbino S, Profita M, Gjomarkaj M: Leptin and leptin receptor expression in asthma. J Allergy Clin Immunol 2009;124:230-237.

48 Bergen HT, Cherlet TC, Manuel P, Scott JE: Identification of leptin receptors in lung and isolated fetal type II cells. Am J Respir Cell Mol Biol 2002;27:71-77.

49 Oyama LM, do Nascimento CM, Carnier J, de Piano A, Tock L, de Lima Sanches P, Gomes FAC, Tufik S, de Mello MT, Dâmaso AR: The role of anorexigenic and orexigenic neuropeptides and peripheral signals on quartiles of weight loss in obese adolescents. Neuropeptides 2010;44:467-474. 
50 Wolf AM, Wolf D, Rumpold H, Enrich B, Tilg H: Adiponectin induces the anti-inflammatory cytokines IL-10 and IL-1RA in human leukocytes. Biochem Biophys Res Commun 2004;323:630-635.

51 Hakala K, Stenius-Aarniala B, Sovijärvi A: Effects of weight loss on peak flow volumes in obese patients with asthma. Chest 2000;118:1315-1321.

-52 Stenius-Aarniala B, Poussa T, Kvarnström J, Grönlund EL, Ylikahri M, Mustajoki P: Immediate and long term effects of weight reduction in obese people with asthma: randomized controlled study. BMJ 2000;320: 827-832.

53 Aaron SD, Fergusson D, Dent R, Chen Y, Vandemheen KL, Dales RE: Effect of weight reduction on respiratory function and airway reactivity in obese women. Chest 2004;125:2046-2052.

54 Wright A, Lavoie KL, Jacob A, Rizk A, Bacon SL: Effect of body mass index on self-reported exercise-triggered asthma. Phys Sportsmed 2010;38:61-66. 